Portland State University

PDXScholar

7-1-1980

\title{
Pressure Dependence of Fluorescent and Photolytic Interferences in HO Detection by Laser-Excited
} Fluorescence

Thomas M. Hard

Portland State University

Robert J. O'Brien

Portland State University

T. B. Cook

Follow this and additional works at: https://pdxscholar.library.pdx.edu/chem_fac

Part of the Other Chemistry Commons, and the Physics Commons Let us know how access to this document benefits you.

\section{Citation Details}

Hard, T. M., O'Brien, R. J., \& Cook, T. B. (1980). Pressure dependence of fluorescent and photolytic interferences in $\mathrm{HO}$ detection by laser-excited fluorescence. Journal Of Applied Physics, 51(7), 3459-3464.

This Article is brought to you for free and open access. It has been accepted for inclusion in Chemistry Faculty Publications and Presentations by an authorized administrator of PDXScholar. Please contact us if we can make this document more accessible: pdxscholar@pdx.edu. 


\section{Pressure dependence of fluorescent and photolytic interferences in $\mathrm{HO}$ detection by laser-excited fluorescence}

T.M. Hard and R.J. O'Brien

Environmental Sciences Program and Department of Chemistry

T.B. Cook

Department of Engineering and Applied Science, Portland State University, Portland, Oregon 97207

(Received 1 October 1979; accepted for publication 27 December 1979)

In the measurement of HO concentrations by laser-excited fluorescence, expansion of the sampled air offers a way to reduce fluorescent and photolytic interference by other species. The decrease in [HO] upon expansion is balanced by an increase in $\mathrm{HO}$ fluorescence yield over a wide range of pressures. Background air fluorescence is reduced if the responsible species have fluorescence yields higher than those of HO. Preliminary experiments indicate that most of the fluorescence observed in laboratory air is due to such species. Upon expansion, the suppression of fluorescent interference can be no greater than the reduction in pressure, whereas the suppression of photolytic interference can be no less.

PACS numbers: $33.50 . \mathrm{Dq}, 35.80 .+\mathrm{s}$, 82.80.Di

\section{INTRODUCTION}

In the detection of gaseous species whose fluorescence is strongly quenched, no decrease in fluorescence signal is produced by expansion of the gas over a considerable range of total pressures. This is due to compensation of lower concentration by higher fluorescence yield at reduced pressure. Since many interferences can be shown to decrease with expansion, this principle should prove useful in atmospheric concentration measurements, in flames, or elsewhere. This paper develops the theory of interference suppression for the detection of hydroxyl radical (HO) in ambient air. Reactions with hydroxyl control the chemical lifetimes of most trace gases emitted into the atmosphere, and thus the measurement of ambient $\mathrm{HO}$ concentrations is important. HO detection has been achieved by laser-excited fluorescence. ${ }^{1-3}$ Since the detection sensitivity is limited by the fluorescence of other ambient species as yet unidentified,,$^{1,4}$ and by photolytic production of spurious $\mathrm{HO}^{2,4-6}$ application of these principles should prove beneficial.

We also report some simple experimental tests of these principles for $\mathrm{HO}$ detection in a source sampled at $1 \mathrm{~atm}$ total pressure. Further advantages of the expansion method are discussed as well.

\section{THEORY}

In the laser-excited fluorescence detection of $\mathrm{HO}$ at atmospheric pressure, collisional quenching of excited HO predominates over spontaneous emission. In the absence of saturation, the laser-excited fluorescence signal detected at $309 \mathrm{~nm}$ is

$$
S_{\mathrm{HO}}=\left\{F \theta \sigma_{N N^{\prime}}\left(n_{N} / n\right)[\mathrm{HO}]\right\} \Delta t Y_{\mathrm{HO}} G .
$$

The expression in braces is the rate of production of electronically-excited HO per unit volume by a 282 -nm photon flux $F$, pumping an $\mathrm{HO}$ rotational line of the transition $\boldsymbol{A}^{2} \boldsymbol{\Sigma}^{+}$ $(v=1) N^{\prime} \leftarrow X^{2} \Pi(v=0) N . \theta$ is the spectral overlap of $F$ with the HO absorption cross section $\sigma_{N N^{\prime}} \cdot\left(n_{N} / n\right)$ is the fractional occupancy of the pumped level $N$, and [HO] is the hydroxyl concentration in molecules $\mathrm{cm}^{-3}$. The 282-nm pulsewidth is $\Delta t$, and $G$ represents the efficiency of collection, spectral filtering, and detection. The fluorescence yield $Y_{\mathrm{HO}}$ is

$$
Y_{\mathrm{HO}}=\frac{A_{\mathrm{HO}}}{A_{\mathrm{HO}}+k_{\mathrm{HO}}^{Q}[M]}=\frac{1}{1+\left(k \frac{\mathrm{HO}}{Q} / A_{\mathrm{HO}}\right)[M]},
$$

where $A_{\mathrm{HO}}=1.4 \times 10^{6} \mathrm{~s}^{-1}$ is the spontaneous emission rate ${ }^{7-9}$ of the excited state $A, k \stackrel{Q}{Q} \mathrm{O}=4.0 \times 10^{-11} \mathrm{~cm}^{3} \mathrm{~s}^{-1}$ is the rate constant for collisional electronic quenching of $A$ by air at $50 \%$ relative humidity based on measurements obtained at low pressure ${ }^{9,10}$, and $[M]$ is the air number density in molecules $\mathrm{cm}^{-3}$.

In terms of the mole fraction $X \equiv[\mathrm{HO}] /[M]$,

$$
S_{\mathrm{HO}} \alpha \frac{A_{\mathrm{HO}}[M]}{A_{\mathrm{HO}}+k_{\mathrm{HO}}^{Q}[M]} X_{\mathrm{HO}} \text {. }
$$

If air containing $X_{\mathrm{HO}}$ is allowed to expand into a region of lower pressure, the $\mathrm{HO}$ fluorescence signal detected in a given volume is nearly constant over a wide range of pressures. As long as $k \mathrm{HO}_{\mathrm{HO}}^{Q}[M]>A_{\mathrm{HO}}$, Eq. (3) reduces to

$$
S_{\mathrm{HO}} \alpha\left(A_{\mathrm{HO}} / K \stackrel{Q}{\mathrm{HO}}\right) X_{\mathrm{HO}} \text {. }
$$

In other words, after the expansion from ambient to a lower pressure, fewer $\mathrm{HO}$ radicals are available for excitation, but more of those excited survive to fluoresce, leaving the timeintegrated signal almost unchanged.

At sufficiently low pressures, when $k_{\mathrm{HO}}^{O}[M]<A_{\mathrm{HO}}$,

$S_{\mathrm{HO}} \alpha[M] X_{\mathrm{HO}}$,

and the detected fluorescence declines with pressure. A useful boundary between these two regions of behavior is the pressure at which the quenching and radiative terms in the denominator of Eq. (2) are equal, corresponding to the density $[M]=\left(A_{\mathrm{HO}} / K_{\mathrm{HO}}^{Q}\right)$. For $\mathrm{HO}$, this pressure is about $0.0014 \mathrm{~atm}$.

Other fluorescent species behave similarly, giving rise to signals $S_{i}$ and yields $Y_{i}$ that depend on $A_{i}, k_{i}^{Q}$, and $[M]$ in equations like Eqs. (1)-(5). The ratio of the desired HO signal to the unwanted interference by species $i$ is proportional to the ratio of fluorescent yields, i.e., 
$\frac{S_{\mathrm{HO}}}{S_{i}} \alpha \frac{Y_{\mathrm{HO}}}{Y_{i}}=\frac{1+\left(k_{i}^{Q} / A_{i}\right)[M]}{1+\left(k_{\mathrm{HO}}^{Q} / A_{\mathrm{HO}}\right)[M]}$.

This ratio increases with decreasing $[M]$ if

$\frac{A_{i}}{k_{i}^{Q}}>\frac{A_{\mathrm{HO}}}{k_{\mathrm{HO}}^{Q}}$.

The greatest improvement occurs if the air expansion can be carried out over a pressure range where

$\left(A_{\mathrm{i}} / k_{i}^{Q}\right)>[M]>\left(A_{\mathrm{HO}} / k_{\mathrm{HO}}^{Q}\right)$. Then

$$
\frac{S_{\mathrm{HO}}}{S_{i}} \alpha 1 /[M] \text {. }
$$

Of course, not all fluorescent species satisfy Eq. (7). An example is $\mathrm{SO}_{2}$, for which the boundary pressure is on the order of $10^{-5} \mathrm{~atm}$ for excitation at $266 \mathrm{~nm} .{ }^{11}$ Since the interfering species under 282-nm excitation are unknown, their collective behavior must be found by experiment.

Another troublesome interference is photolytic $\mathrm{HO}$, which can be produced by $282-\mathrm{nm}$ photolysis of other substances, followed by laser-excited fluorescence detection within the same laser pulse. It is assumed that the air in the detection zone is replaced between pulses. The HO signal that results from photolytic production, followed by laserexcited fluorescence, is proportional to $F^{2}$. $F$, the flux in photons $\mathrm{cm}^{-2} \mathrm{~s}^{-1}$, can be reduced by enlarging the cross sectional area of the laser beam, ${ }^{6}$ at the cost of reduction in the product $F G$ in Eq. (1) if the fluorescence detection system is steradiance limited, leading to a loss in the desired signal. Air expansion offers an alternative way to suppress photolytic interference.

To treat this interference, we first consider the 282-nm photolysis of a hydroxyl-containing species ROH (HONO, $\mathrm{HNO}_{3}, \mathrm{HOCl}$, or a hydroperoxide):

$$
\begin{aligned}
& \mathrm{ROH}+h v \stackrel{J_{1}}{\rightarrow} R+\mathrm{HO}^{+} \\
& \mathrm{HO}^{\dagger}+M \stackrel{k_{2}}{\rightarrow} \mathrm{HO}+M,
\end{aligned}
$$

where $\mathrm{HO}^{+}$represents $\mathrm{HO}\left(X^{2} \mathrm{II}\right)$ whose vibrational and rotational distributions are not yet thermalized. The production of detectable $\mathrm{HO}$ within the laser pulsewidth $\Delta t$ is

$$
\begin{aligned}
& {[\mathrm{HO}]_{\mathrm{R} 1}=\alpha_{1} \beta_{1}} \\
& \alpha_{1} \equiv J_{1}[\mathrm{ROH}] \Delta t=J_{1} X_{\mathrm{ROH}}[M] \Delta t \\
& \beta_{1} \equiv 1-\frac{1-\exp \left[-k_{2}(M) \Delta t\right]}{k_{2}[M] \Delta t} .
\end{aligned}
$$

The steady-state expression $\alpha_{1}$ (meaning steady growth in $[H O]_{\mathrm{R} I}$ with $\left.\Delta t\right)$ is proportional to $[M]$, so it decreases linearly with pressure upon air expansion. The transient expression $\beta_{1}$ corrects for the relaxation of $\mathrm{HO}^{\dagger}$ via reaction $R 2$, and leads to a further reduction in $[\mathrm{HO}]_{\mathrm{R} 1}$ with decreasing $[M]$. The pressure dependence of $\beta_{1}$ is shown in Fig. 1 for $\Delta t=8 \mathrm{~ns}$ and various values of $k_{2}$.

Photolytic HO can also be produced by the $282-\mathrm{nm}$ pulses via the $\mathrm{O}_{3}-\mathrm{H}_{2} \mathrm{O}$ mechanism, ${ }^{2,4,6}$ which plagued early efforts to observe ambient $\mathrm{HO}$, i.e.,

$$
\mathrm{O}_{3}+h v \stackrel{J_{1}}{\rightarrow} \mathrm{O}_{2}+\mathrm{O}\left({ }^{1} \mathrm{D}\right)
$$

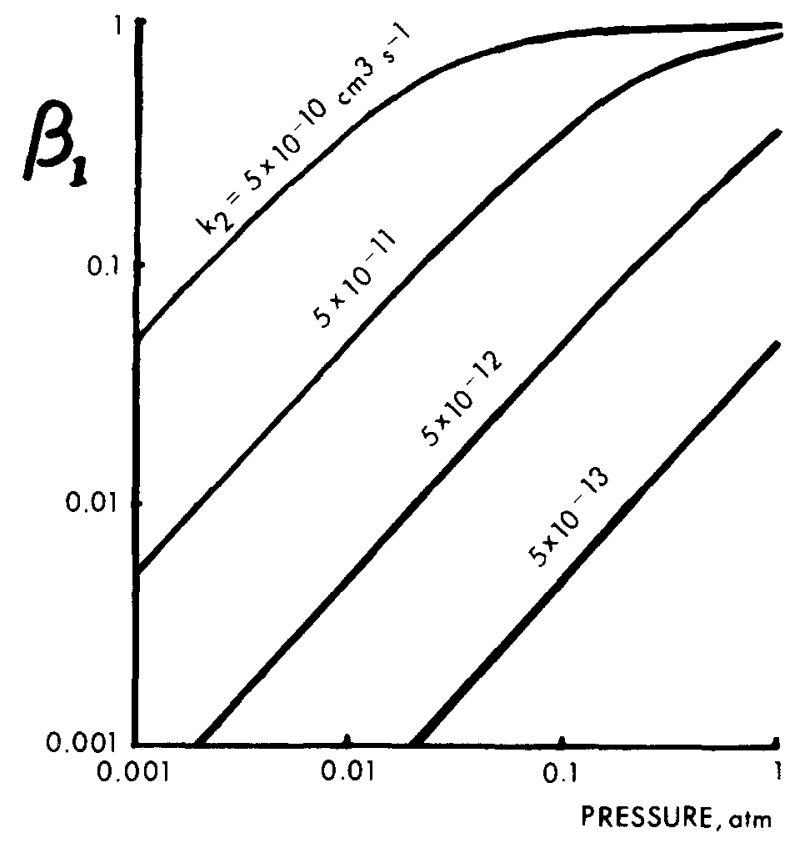

FIG. 1. Pressure dependence of $\beta_{1}$, the transient correction for detectable HO generated from photolysis of a hydroxyl-containing parent molecule, calculated with $\Delta t=8 \mathrm{~ns}$ and several values of $k_{2}$.

$$
\begin{aligned}
& \mathrm{O}\left({ }^{1} \mathrm{D}\right)+M^{k_{4}} \rightarrow \mathrm{O}\left({ }^{3} \mathrm{P}\right)+M \\
& \mathrm{O}\left({ }^{3} \mathrm{P}\right)+\mathrm{O}_{2}+M_{k_{\mathrm{s}}}^{\rightarrow} \mathrm{O}_{3}+M \\
& \mathrm{O}\left({ }^{1} \mathrm{D}\right)+\mathrm{H}_{2} \mathrm{O} \stackrel{k_{\mathrm{s}}}{\rightarrow} 2 \mathrm{HO}^{\dagger}
\end{aligned}
$$

This sequence is then followed by relaxation of $\mathrm{HO}^{+}$via reaction R2. To find the production of detectable $\mathrm{HO}$ within $\Delta t$, we integrate the differential equations for $\left[\mathrm{O}\left({ }^{1} \mathrm{D}\right)\right],\left[\mathrm{HO}^{\dagger}\right]$, and $[\mathrm{HO}]$ in succession and obtain ${ }^{12}$

$$
\begin{aligned}
& {\left[\mathrm{HO}_{\mathrm{R} 3}=\alpha_{3} \beta_{3}\right. \text {, }} \\
& \alpha_{3} \equiv \frac{2 J_{3} k_{6}\left[\mathrm{O}_{3}\right]\left[\mathrm{H}_{2} \mathrm{O}\right]}{k_{4}[M]+k_{6}\left[\mathrm{H}_{2} \mathrm{O}\right]} \Delta t=\frac{2 J_{3} k_{6}}{k_{4}^{\prime}} X_{\mathrm{O}_{2}} X_{H_{2} \circ}[M] \Delta t \text {, } \\
& \beta_{3} \equiv 1-\left[1 / k_{4}^{\prime}-k_{2}\right] \\
& \times\left[k_{4}^{\prime}\left(\frac{1-\exp \left(-k_{2}[M] \Delta t\right)}{k_{2}[M] \Delta t}\right)\right. \\
& \left.-k_{2}\left(\frac{1-\exp \left(-k_{4}^{\prime}[M] \Delta t\right)}{k_{4}^{\prime}[M] \Delta t}\right)\right]
\end{aligned}
$$

where $k_{4}^{\prime}=k_{4}+k_{6} X_{\mathrm{H}_{2} \mathrm{O}}$. Since the steady state expression $\alpha_{3}$ is proportional to $X_{\mathrm{O}_{3}} X_{\mathrm{H}_{2} \mathrm{O}}[M]$, it decreases linearly with pressure upon air expansion, like $\alpha_{1}$. $\beta_{3}$ corrects for the failure of the intermediates $\mathrm{O}\left({ }^{1} \mathrm{D}\right)$ and $\mathrm{HO}^{\dagger}$ to reach their steady-state concentrations within $\Delta t$, and it also decreases during expansion in the pressure range of interest. The variation of $\beta_{3}$ with pressure is plotted in Fig. 2, with $\Delta t=8 \mathrm{ns,}$ $k_{4}^{\prime}=3 \times 10^{-11} \mathrm{~cm}^{3} \mathrm{~s}^{-1}$, and several values of $k_{2}$.

$k_{2}$ depends on the nature of $\mathrm{HO}^{+}$, which consists of $X(v \geqslant 0)(N>1)$. Collisional relaxation rate constants for the rotational and lower vibrational levels of the $X$ state have not been reported. Vibrational relaxation rates might be anywhere in the range between that observed ${ }^{13}$ in $X(v>4)$, $k>7.8 \times 10^{-14} \mathrm{~cm}^{3} \mathrm{~s}^{-1}$, and the much faster rate observed ${ }^{10}$ in $A(v=0<-1), k=8.9 \times 10^{-11} \mathrm{~cm}^{3} \mathrm{~s}^{-1}$. Rotational relax- 


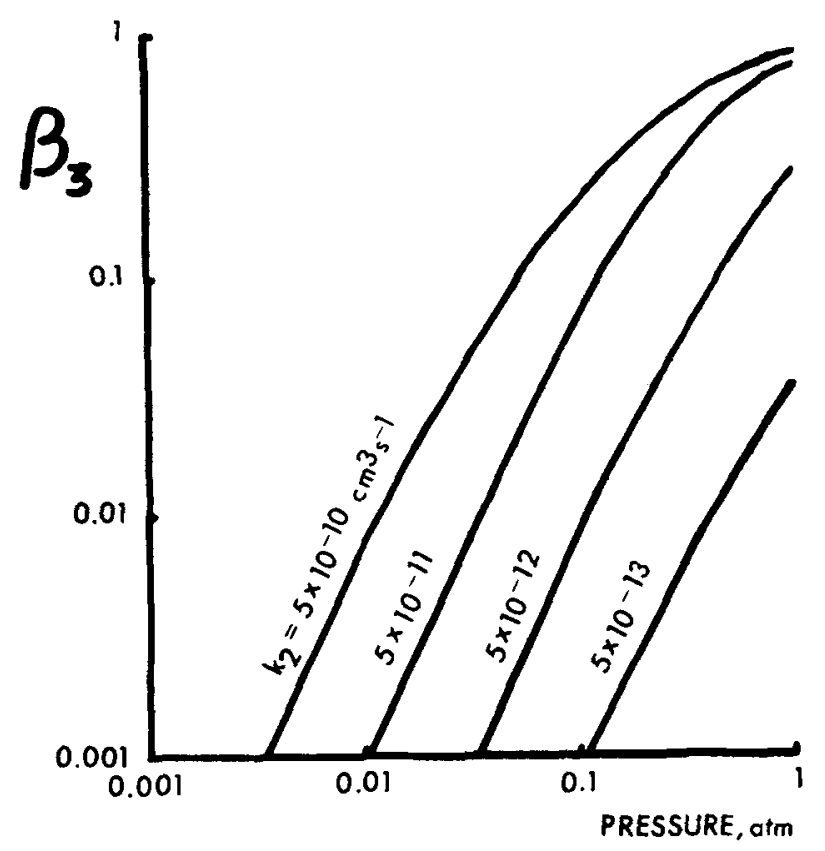

FIG. 2. Pressure dependence of $\beta_{3}$, the transient correction for detectable $\mathrm{HO}$ generated from photolysis of $\mathrm{O}_{3}$ in the presence of $\mathrm{H}_{2} \mathrm{O}$, calculated with $\Delta t=8 \mathrm{~ns}, k_{4}^{\prime}=3 \times 10^{-11} \mathrm{~cm}^{3} \mathrm{~s}^{-1}$, and several values of $k_{2}$.

ation in $X(v=0)$ may be as fast as that observed ${ }^{14}$ in $A(v=0), k \simeq 5 \times 10^{-10} \mathrm{~cm}^{3} \mathrm{~s}^{-1}$, which is near the collision rate. If so, then rotational relaxation in $X(v=0]$ is the earliest, and probably the principal, channel that feeds the pumped level $(N=1$ or 2) within $\Delta t$, at pressures of 1 atm and below. ${ }^{15}$ With $k_{2}=5 \times 10^{-10} \mathrm{~cm}^{-3} \mathrm{~s}^{-1}$, Eq. (10) predicts a steep decline in spurious $\mathrm{HO}$ upon air expansion. Relative to that at $1 \mathrm{~atm},[\mathrm{HO}]_{\mathrm{R} 3}$ is down by a factor of 40 at $0.1 \mathrm{~atm}$ and a factor of $10^{4} \mathrm{at} 0.01 \mathrm{~atm}$. For slower $\mathrm{HO}^{\dagger}$ relaxation, the relative improvement is even greater.

In sum, the expansion of air from 1 atm to a pressure $P>0.0014$ atm should leave the time-integrated HO fluorescence nearly constant, as in Eq. (4). Meanwhile, fluorescent interference declines for all species whose $\left(A_{i} / k_{i}\right)$ is higher than that of HO, in accordance with Eq. (6). Photolytic HO interference declines more steeply than the pressure, due to the steady-state and transient effects in Eqs. (9) and (10). Thus air expansion makes possible a significant improvement in sensitivity to ambient $\mathrm{HO}$ in the presence of fluorescent and photolytic interferences. Rayleigh, Raman, and Mie (particulate) scattering, normally removed by spectral filtering, are of course reduced by the expansion. They are synchronous with the 282-nm pulse, while the HO fluorescence decay time varies as $[M]^{-1}$. Thus it may become feasible to replace spectral with temporal discrimination, removing the rather stringent light-gathering limitations of monochromators and multilayer dielectric filters.

To the extent that the air is cooled by the expansion, the fractional occupancy $\left(n_{1} / n\right)$ of the $X(v=0)(N=1)$ level improves and the rate constant $k^{Q}$ may decrease. Homogeneous reactions affecting the chemical lifetime of $\mathrm{HO}$ are retarded, mainly by their concentration dependence.

The HO laser-excited fluorescence mechanism is capable of saturation of the absorbing transition, as observed at low pressure. ${ }^{16}$ Such behavior may limit the advantages to be gained from air expansion.

\section{EXPERIMENT DESIGN}

One method of obtaining the desired expansion is to use an orifice leading from the atmosphere to a flow tube evacuated by a pump. The pressure in the flow tube can be controlled by varying the pumping speed with a valve between the flow tube and the pump, and by changing the conductance of the orifice.

The major disadvantage of the orifice-flow tube method is its use of surfaces in proximity to the sampled air, inviting HO loss by surface reactions as well as fluorescence of flow tube components. Both can be avoided somewhat by proper design. We consider a cylindrical tube of radius $r$, with a 282$\mathrm{nm}$ beam of much smaller radius following the tube axis. The HO fluorescence is observed at an axial distance $z$ downstream from the orifice. Air enters the orifice at standard volume flow rate $\dot{V}_{o}$ and reaches the detection zone in a transit time shorter than $t=\left(\pi r^{2}[M] z\right) / \dot{V}_{o}[M]_{o}$. Ignoring temperature effects, we approximate the radial diffusion distance $\Delta r$ during transit by the random-walk formula

$$
\begin{aligned}
\overline{\Delta r^{2}} & =\frac{2}{3} \lambda \bar{w} t \\
& =\frac{2}{3}\left(\frac{1}{\pi \sqrt{2}[M] d^{2}}\right) \bar{w}\left(\frac{\pi r^{2}[M] z}{\dot{V}_{0}[M]_{0}}\right) \\
& =\left(2.1 \times 10^{-4} m^{2} s^{-1}\right)\left(r^{2} z / \dot{V}_{0}\right),
\end{aligned}
$$

$\lambda=$ mean free path, $\bar{w}=$ average thermal speed, and $d=$ effective molecular diameter. In this approximation, $\Delta r$ is independent of flow tube pressure.

For the foregoing to be valid, the higher radial transport rates of turbulent flow must be avoided. The criterion for nonturbulent flow is

$\dot{V}_{o}<770 \pi r \eta=\left(4.4 \times 10^{-2} \mathrm{~m}^{2} \mathrm{~s}^{-1}\right) r$,

where $\eta$ is the air viscosity. Once nonturbulent flow has been established in the flow tube, a very conservative criterion to prevent reactions at the wall from depleting [HO] observed near the axis is $\overline{\Delta r^{2}}<r^{2}$. With Eqs. (11) and (12) we obtain

$$
\left(4.4 \times 10^{-2} \mathrm{~m}^{2} \mathrm{~s}^{-1}\right) r>\dot{V}_{o}>\left(2.1 \times 10^{-4} \mathrm{~m}^{2} \mathrm{~s}^{-1}\right) z
$$

These criteria permit the selection of practical orifice conductances and flow tube dimensions.

\section{EXPERIMENTAL TESTS}

To determine whether the orifice-flow tube method transmits useful $\mathrm{HO}$ concentrations and whether fluorescent interferences are in fact reduced, we conducted experiments with an artificial $\mathrm{HO}$ source and with indoor air.

In the fluorescence excitation system, a Rh6G dye laser oscillator and two amplifiers are sidepumped by a frequency-doubled Nd-YAG laser. The oscillator cavity, $60 \mathrm{~cm}$ long, is tuned by a 316 grooves $/ \mathrm{mm}$ echelle grating in 9 th order. The dye-laser output is frequency doubled by an angle-tuned ammonium dihydrogen phosphate crystal. The resulting 282-nm pulses have a width of $8 \mathrm{~ns}$, and for these experiments, have an energy of $0.1 \mathrm{~mJ}$ and spectral FWHM 


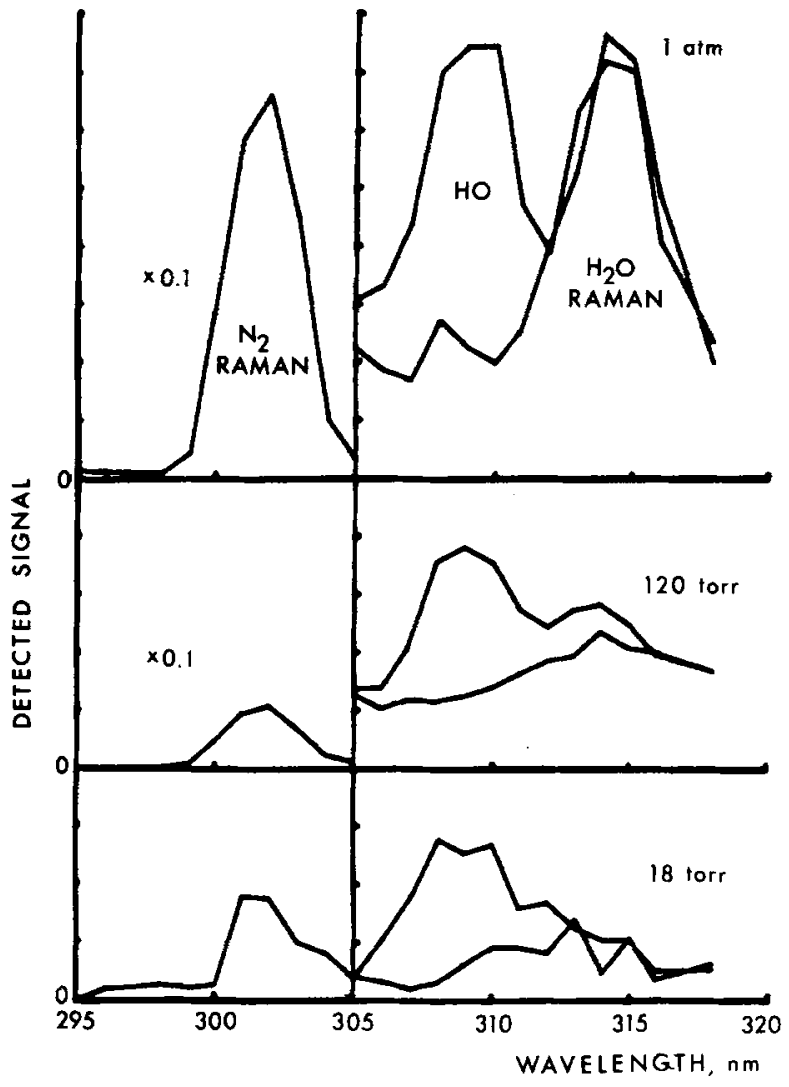

FIG. 3. Spectra excited at $282 \mathrm{~nm}$, obtained using a flowing HO source mixed with room air at $1 \mathrm{~atm}$, and sampled by an orifice leading to a flow tube maintained at 120 and 18 Torr. At each pressure, upper curve is with excitation at $Q_{1} 1$ line center and lower curve is with excitation $3.0 \mathrm{~cm}^{-1}$ lower in frequency. At 1 atm and at 120 Torr, 295-305-nm signals are 10 times larger than displayed.

of $1.3 \mathrm{~cm}^{-1}$. At the $\mathrm{HO}$ detection zone, the $282-\mathrm{nm}$ beam is 2 $\mathrm{mm}$ in diameter. Fluorescence is collected at right angles to the beam direction, and the beam polarization is perpendicular to the plane of observation, permitting calibration via $\mathrm{N}_{2}$ Raman scattering. A 2-cm length of the beam is imaged by a Suprasil lens upon the entrance slit of an $f / 3.5$ grating monochromator whose bandpass is $2.8 \mathrm{~nm}$ at $209 \mathrm{~nm}$. Cellulose triacetate film ${ }^{17}$ is inserted immediately after the lens to reject scattered 282-nm radiation. The transmission of commercial samples of cellulose triacetate is irregular with thickness; the optical density of the $0.4-\mathrm{mm}$ film used here is 5.0 , 0.35 , and 0.27 at $282,302.5$, and $309 \mathrm{~nm}$, respectively.

The monochromator output is detected by a Hamamatsu R955 photomultiplier, amplified, sampled with a 1$\mathrm{MHz}$ bandwidth track-and-hold, and subsequently digitized. A microprocessor-based control system integrates the signal from 250 successive laser pulses and transmits the result to a teletypewriter.

The central section of the flow tube, including the orifice and the detection zone, is demountable. Our early experiments with Pyrex tubes taught us how to construct the orifice for good HO transmission. The best results were obtained by heating the tube wall with a torch, using a fine rod to draw a narrow conical sidearm from the wall, then breaking the sidearm cleanly and flame-polishing its edges slightly. An orifice drawn at a small angle from the tube wall gave much better HO transmission than one drawn perpendicularly.

To avoid the fluorescence of Pyrex, a single Suprasil version of the central section was used in all experiments described below. At flow tube pressures below 600 Torr, the measured air flow through the orifice is $\dot{V}_{o}=90 \mathrm{~cm}^{3} \mathrm{~s}^{-1}$. The orifice's inner diameter is $0.7 \mathrm{~mm}$, the sidearm's radial and axial extensions from the flow tube wall are 2 and $6 \mathrm{~mm}$, respectively, and the flow tube's inner radius is $10 \mathrm{~mm}$.

The 282-nm beam enters the tube upstream from the orifice through a Suprasil Brewster window, whose smallangle forward scatter is cut by two apertures. Flow tube pressures are measured in this nonflowing section. Several $\mathrm{cm}$ downstream from the detection zone, the tube widens and bends at the exit Brewster window. The air flow proceeds through a large flow-restricting valve to a vacuum pump. At the lowest measured pressure, 18 Torr, some pressure drop between the orifice and the detection zone is expected, but is ignored in the present data. Also, the flow velocities attained in these experiments are not expected to yield large temperature drops.

$\mathrm{HO}$ is generated at ambient pressure by bubbling $\mathrm{N}_{2}$ through $\mathrm{H}_{2} \mathrm{O}$ maintained at $21^{\circ} \mathrm{C}$ and passing the mixture through the annular space between an OZ4T5 $\mathrm{Hg}$ lamp (BHK, Inc.) and a concentric Pyrex jacket. The HO outlet is a short, 8-mm i.d. radial extension from the wall of the jacket. The outlet is placed $4 \mathrm{~mm}$ from the tube orifice, or when the flow tube central section is removed for 1-atm experiments, $6 \mathrm{~mm}$ from the center of the detection zone. HO concentrations on the order of $10^{10} \mathrm{~cm}^{-3}$ are generated.

Spectra of the resulting resonant and nonresonant signals, obtained by hand-scanning the monochromator during a period of several hours, are shown in Fig. 3. The 1-atm

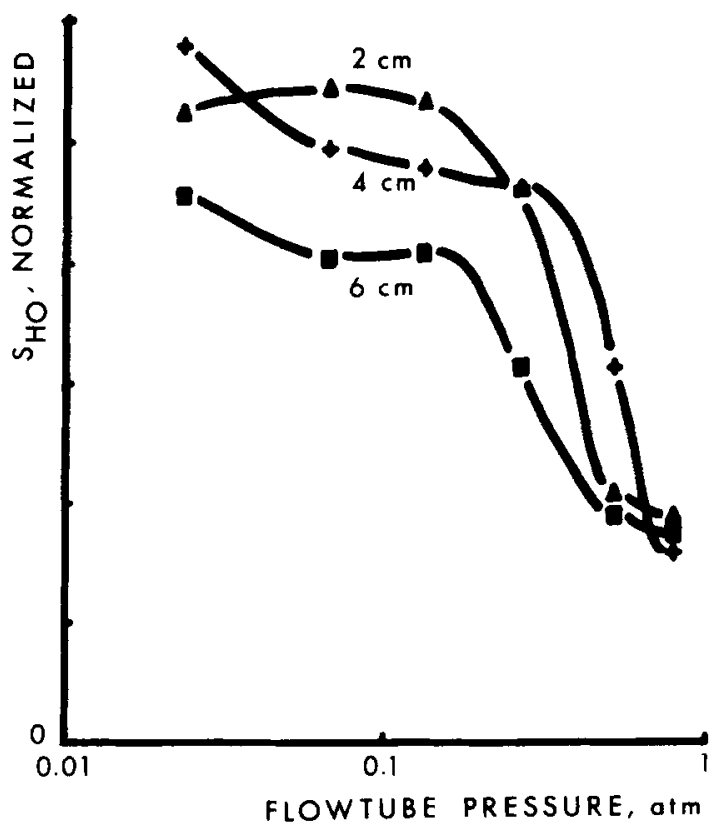

FIG. 4. HO laser-excited fluorescence, observed as a function of flow tube pressure from 18 to 600 Torr, divided by $\mathrm{N}_{2}$ Raman intensity observed at 50 Torr, at various distances between sampling orifice and center of detection zone. 
spectra are not comparable with those obtained from the flow tube at 120 and 18 Torr, because of differences in both transit time from the HO source to the sampling region and dilution by laboratory air. Besides the obvious reduction in $\mathrm{N}_{2}$ and $\mathrm{H}_{2} \mathrm{O}$ Raman scattering, there is a substantial reduction in fluorescent background at $309 \mathrm{~nm}$.

The HO signal $S_{\text {HO }}$ is measured as the difference between the detected 309-nm fluorescence excited at the line center of $Q_{1} 1[A(v=1)(N=1) \leftarrow X(v=0),(N=1)]$ minus that excited at a frequency $3.0 \mathrm{~cm}^{-1}$ lower. At both $1 \mathrm{~atm}$ and $18 \mathrm{Torr}, S_{\mathrm{HO}}$ is found to be linear in the 282-nm pulse energy. This means that the detection system responds linearly, which is confirmed by linearity of the $\mathbf{N}_{2}$ Raman signal with flow tube pressure; that photolytic interferences are absent; and that the $\mathrm{HO}$ absorption is not near saturation.

Figure 4 shows the dependence of $S_{\text {HO }}$ on flow tube pressure, with the detection zone positioned at various distances downstream. To compensate for imperfect optical realignment, $S_{\mathrm{HO}}$ is normalized by the $\mathrm{N}_{2}$ Raman signal measured at 50 Torr at each position. $S_{\mathrm{HO}}$ varies little with distance at any given pressure, in agreement with the criteria of Eq. (13). Thus the factor-of-3 increase in $S_{\mathrm{HO}}$ between 600 and 18 Torr is not explained by reactions at the wall from 2 to $6 \mathrm{~cm}$ downstream. Wall losses in a turbulent region nearer to the orifice would vary with transit time, and might account for the observed variation of $S_{\mathrm{HO}}$ with flow tube pressure.

With the HO source removed, we observe the background fluorescence of room air, excited at $282 \mathrm{~nm}$ and detectd at $309 \mathrm{~nm}$, as a function of flow tube pressure. For a single fluorescent substance, the conventional Stern-Volmer equation is

$$
I_{\text {abs }} / I_{\mathrm{f}}=1 / Y_{\mathrm{i}}=1+\left(k_{i}^{Q} / A_{i}\right)[M] .
$$

In air expansion, mole fractions are unchanged, unlike the usual studies in which quenching gas is added to a constant concentration of fluorescent gas. $I_{\mathrm{abs}}=F \sigma_{i} X_{i}[M]$, where $\sigma_{i}$

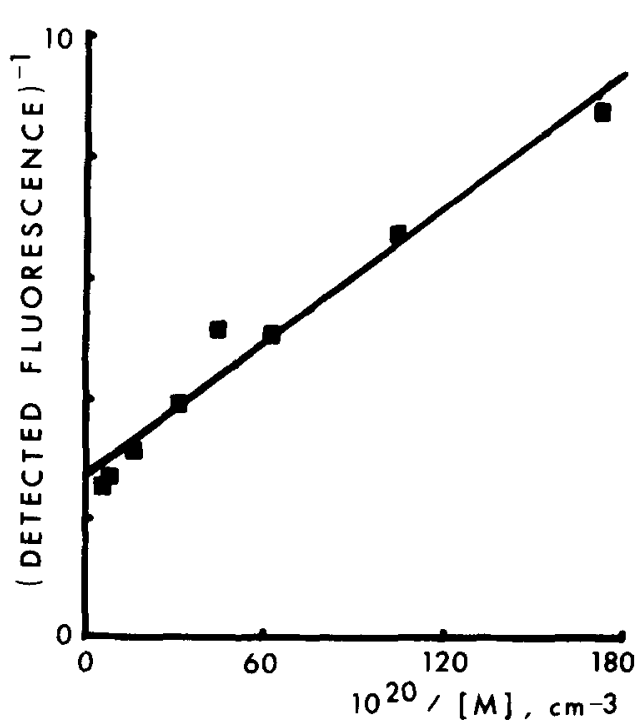

FIG. 5. Stern-Volmer plot of the pressure dependence of the fluorescence of laboratory air, excited at $282 \mathrm{~nm}$ and observed at $309 \mathrm{~nm}$, between 18 and 600 Torr.

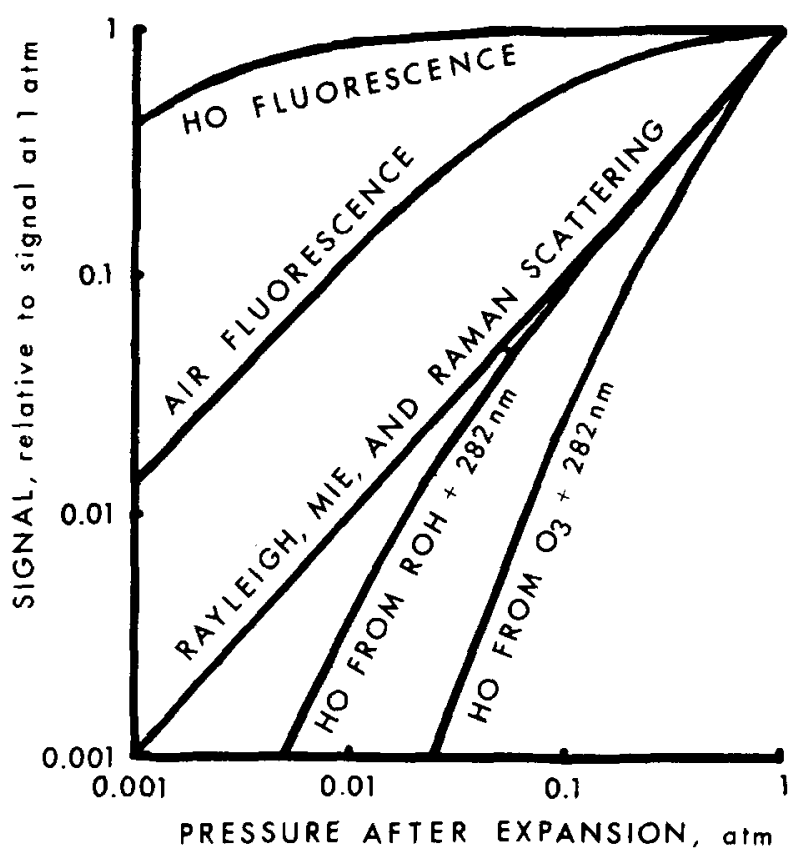

FIG. 6. Pressure dependence of pulsed fluorescence of $\mathrm{HO}$, and of the principal interferences in its detection.

is the absorption cross section of species $i$ at $282 \mathrm{~nm}$, and $I_{\mathrm{f}}$ $=S_{i} / G$, where $G$ is as defined for Eq. (1). Equation (14) can be written

$$
1 / S_{1}=\left(G / F \sigma_{1} X_{i}\right)\left[(1 /[M])+k_{i}^{Q} / A_{i}\right) .
$$

Thus a plot of $1 / S_{i}$ versus $1 /[M]$ should yield a line whose ratio of intercept to slope is $k_{i}^{Q} / A_{i}$.

For a mixture of two or more fluorescent substances, such treatment is wrong in principle, because

$$
1 / \Sigma_{i} S_{i} \neq \Sigma_{i} 1 / S_{i},
$$

where the left-hand side is the experimental observable and the right-hand side is the quantity linear in $1 /[M]$. Thus the Stern-Volmer plot of such a mixture may well be curved. Nonetheless, we find that the room-air fluorescence data, ${ }^{18}$ plotted in Fig. 5, are well represented by Eq. (15). This implies that most of the background is due to a single substance, or a group of substances with about the same $A / k^{Q}$ $=1.4 \times 10^{18} \mathrm{~cm}^{-3}$, which is about 40 times greater than $A_{\mathrm{HO}} / k_{\mathrm{HO}}^{Q}$.

\section{CONCLUDING REMARKS}

The available experimental data ${ }^{6}$ on the pressure dependence of photolytic HO interferences do not adequately test the transient behavior of Eqs. (9) or (10). Suitable tests should yield values of $k_{2}$ for relaxation within $X^{2} \Pi$; such values are also essential to a description of saturation behavior. Moreover, since higher energy and narrower linewidth of our excitation source are anticipated, a search for and study of saturation behavior in the $0.01-1 \mathrm{~atm}$ pressure range would be appropriate.

The expansion-pressure dependences of the desired HO signal and of the principal interferences are summarized in Fig. 6. The uppermost curve is the product of HO concentra- 
tion and fluorescent yield, and does not include wall loss, spectral redistribution of excitation and emission intensities upon expansion, or radiative saturation. The air-fluorescence curve is based upon the experimentally observed $A / k^{Q}$. The two lowermost curves represent Eqs. (9) and (10) with $\Delta t=8 \mathrm{~ns}$ and $k_{2}=5 \times 10^{-10} \mathrm{~cm}^{3} \mathrm{~s}^{-1}$.

Figure 6 emphasizes the divergent behavior of scattering, fluorescent, and photolytic interferences upon expansion. Rayleigh, Raman, and Mie scattering decline in proportion to the pressure. Fluorescence declines less steeply than the pressure, due to reduced competition by collisional quenching of the excited electronic state. Photolytic $\mathrm{HO}$ interference declines more steeply than the pressure, due to slowed collisional relaxation within the ground electronic state.

\section{ACKNOWLEDGMENTS}

We are grateful to G.A. Tsongas and F.M. Young for advice, and to R.A. Doty for help with figure presentation. This work was supported by NSF Grant SER 76-18132.

'C.C. Wang and L.I. Davis, Phys. Rev. Lett. 32, 349 (1974).

${ }^{2}$ C.C. Wang, L.I. Davis, C.H. Wu, S. Japar, H. Niki, and B. Weinstock, Science 189, 797 (1975).
${ }^{3}$ D.D. Davis, W. Heaps, and T. McGee, Geophys. Rev. Lett. 3, 331 (1976). ${ }^{4}$ C.H. Wu, C.C. Wang, S.M. Japar, L.I. Davis, M. Hanabusa, D. Killinger, H. Niki, and B. Weinstock, Int. J. Chem. Kinet. 8, 765 (1976)

${ }^{5}$ C.C. Wang, L.I. Davis, C.H. Wu, and S. Japar, Appl. Phys. Lett. 28, 14 (1976).

${ }^{6}$ M. Hanabusa, C.C. Wang, D.K. Killinger, and W. Fisher, J. Chem. Phys. 66, 2118 (1977).

${ }^{7}$ K.H. Becker and D. Haaks, Z. Naturforsch. 28, 249 (1973)

${ }^{x}$ P. Hogan and D.D. Davis, Chem. Phys. Lett. 29, 555 (1974)

${ }^{9}$ K.R. German, J. Chem. Phys. 62, 2584 (1975); 63, 5252 (1975).

${ }^{10}$ K.R. German, J. Chem. Phys. 64, 4065 (1976),

${ }^{11} \mathrm{~K}$. Schofield, J. Quant. Spectrosc. Radiat. Transfer 17, 13 (1977)

${ }^{12}$ The 282-nm pulse is approximated by a squarewave, as in an earlier derivation. ${ }^{6}$ Our $(1-\exp (-x)) / x$ terms within $\beta_{3}$ of Eq. (10) differ from the corresponding $2[1-[1-\exp (-x)] / x] / x$ terms presented in Eq. A 1 of Ref. 6, and yield different numerical results for practical values of $k_{2}, k_{4}^{\prime}$, $[M]$, and $\Delta t$. Ours agrees with results of nonstiff implicit integration.

${ }^{13}$ G.E. Streit and H.S. Johnston, J. Chem. Phys. 64, 95 (1976).

${ }^{14}$ R.K. Lengel and D.R. Crosley, J. Chem. Phys. 67, 2085 (1977).

${ }^{15}$ Nevertheless, if laser-irradiated air is not replaced by air movement between laser pulses, then the relaxation of vibrationally excited HO produced by previous pulses may greatly increase the observed photolytic interference. Moreover, a priori calculation of absolute ambient interference levels should not be relied on until all major $\mathrm{HO}$ parents have been identified, nor until the production and relaxation of HOX $X(v<4)$ have been studied experimentally.

${ }^{16}$ D.K. Killinger, C.C. Wang, and M. Hanabusa, Phys. Rev. A 132145 (1976)

${ }^{17}$ W.R. McBride, quoted by J. Hennes and L. Dunkelman, in The Middle Ultraviolet, edited by A.E.S. Green (Wiley, New York, 1966), pp. 334 335.

${ }^{18}$ T.M. Hard, R.J. O'Brien, T.B. Cook, and G.A. Tsongas, Appl. Opt. 18, 3216 (1979). 